\title{
The GenoDiabMar Registry: A Collaborative Research Platform of Type 2 Diabetes Patients
}

\author{
Adriana Sierra ${ }^{1}$, Sol Otero ${ }^{2}$, Eva Rodríguez ${ }^{1}$, Anna Faura ${ }^{1}$, María Vera ${ }^{1}$, Marta Riera $\left.{ }^{1}{ }^{(}\right)$, Vanesa Palau ${ }^{1}(\mathbb{D}$, \\ Xavier Durán ${ }^{3}$, Anna Costa-Garrido ${ }^{3}{ }^{1}$, Laia Sans ${ }^{1}$, Eva Márquez ${ }^{1}$, Vladimir Poposki ${ }^{4}$, Josep Franch-Nadal ${ }^{5,6}$, \\ Xavier Mundet ${ }^{5,7} \mathbb{D}$, Anna Oliveras ${ }^{1} \mathbb{D}$, Marta Crespo ${ }^{1}$, Julio Pascual ${ }^{1, \dagger}$ and Clara Barrios ${ }^{1, *}$
}

check for updates

Citation: Sierra, A.; Otero, S.; Rodríguez, E.; Faura, A.; Vera, M.; Riera, M.; Palau, V.; Durán, X.; Costa-Garrido, A.; Sans, L.; et al. The GenoDiabMar Registry: A Collaborative Research Platform of Type 2 Diabetes Patients. J. Clin. Med. 2022, 11, 1431. https://doi.org/ $10.3390 /$ jcm11051431

Academic Editor: Alberto Barcelo

Received: 20 December 2021

Accepted: 2 March 2022

Published: 5 March 2022

Publisher's Note: MDPI stays neutral with regard to jurisdictional claims in published maps and institutional affiliations.

Copyright: (C) 2022 by the authors. Licensee MDPI, Basel, Switzerland. This article is an open access article distributed under the terms and conditions of the Creative Commons Attribution (CC BY) license (https:// creativecommons.org/licenses/by/ $4.0 /)$.
1 Department of Nephrology, Hospital del Mar, Institut Hospital del Mar d'Investigacions Mèdiques, 08003 Barcelona, Spain; asierra@psmar.cat (A.S.); erodriguezg@psmar.cat (E.R.); afaura@psmar.cat (A.F.); mvera@psmar.cat (M.V.); mriera1@imim.es (M.R.); vpalau@imim.es (V.P.); lsans@psmar.cat (L.S.); eva.marquez.mosquera@psmar.cat (E.M.); aoliveras@psmar.cat (A.O.); mcrespo@psmar.cat (M.C.); julpascual@gmail.com (J.P.)

2 Department of Nephrology, Consorci Sanitari Alt Penedès-Garraf, 08800 Barcelona, Spain; sospetita@hotmail.com

3 Methodological and Biostatistical Advisory Service, Institut Hospital del Mar d'Investigacions Mèdiques, 08003 Barcelona, Spain; xduran@imim.es (X.D.); anna.costaga@e-campus.uab.cat (A.C.-G.)

4 Department of Ophthalmology, Hospital del Mar, Institut Hospital del Mar d'Investigacions Mèdiques, 08003 Barcelona, Spain; vpoposki@psmar.cat

5 Research Support Unit, University Institute for Research in Primary Care, Jordi Gol (IDIAP Jordi Gol), 08041 Barcelona, Spain; josep.franch@gmail.com (J.F.-N.); xmundet.bcn.ics@gencat.cat (X.M.)

6 Biomedical Research Centre in Diabetes and Associated Metabolic Disorders (CIBERDEM), 28029 Barcelona, Spain

7 Departamento de Medicina, Universidad Autonoma de Barcelona, 08193 Bellaterra, Spain

* Correspondence: cbarrios@psmar.cat or clarabarrios@hotmail.es; Tel.: +34-65-004-2149

+ Current address: Department of Nephrology, Hospital Universitario 12 de Octubre, 28041 Madrid, Spain.

Abstract: The GenoDiabMar registry is a prospective study that aims to provide data on demographic, biochemical, and clinical changes in type 2 diabetic (T2D) patients attending real medical outpatient consultations. This registry is also used to find new biomarkers related to the micro- and macrovascular complications of T2D, with a particular focus on diabetic nephropathy. With this purpose, longitudinal serum and urine samples, DNA banking, and data on 227 metabolomics profiles, 77 immunoglobulin $\mathrm{G}$ glycomics traits, and other emerging biomarkers were recorded in this cohort. In this study, we show a detailed longitudinal description of the clinical and analytical parameters of this registry, with a special focus on the progress of renal function and cardiovascular events. The main objective is to analyze whether there are differential risk factors for renal function deterioration between sexes, as well as to analyze cardiovascular events and mortality in this population. In total, 650 patients with a median age of 69 (14) with different grades of chronic kidney diseaseG1-G2 (eGFR > 90-60 mL/min/1.73 m²) 50.3\%, G3 (eGFR; 59-30 mL/min/1.73 m²) 31.4\%, G4 (eGFR; 29-15 mL/min/1.73 $\mathrm{m}^{2}$ ) 10.8\%, and G5 (eGFR < $15 \mathrm{~mL} / \mathrm{min} / 1.73 \mathrm{~m}^{2}$ ) 7.5\%-were followed up for 4.7 (0.65) years. Regardless of albuminuria, women lost 0.93 (0.40-1.46) fewer glomerular filtration units per year than men. A total of $17 \%$ of the participants experienced rapid deterioration of renal function, $75.2 \%$ of whom were men, with differential risk factors between sexes-severe macroalbuminuria > $300 \mathrm{mg} / \mathrm{g}$ for men OR [IQ] 2.40 [1.29:4.44] and concomitant peripheral vascular disease 3.32 [1.10:9.57] for women. Overall mortality of $23 \%$ was detected ( $38 \%$ of which was due to cardiovascular etiology). We showed that kidney function declined faster in men, with different risk factors compared to women. Patients with T2D and kidney involvement have very high mortality and an important cardiovascular burden. This cohort is proposed as a great tool for scientific collaboration for studies, whether they are focused on T2D, or whether they are interested in comparing differential markers between diabetic and non-diabetic populations. 
Keywords: type 2 diabetes; real-world patient registry; epidemiology; diabetes complication; renal function; sex differences; multiomic collaborative platform

\section{Introduction}

Diabetes mellitus is of pandemic proportions, affecting more than 450 million people worldwide, of whom up to $95 \%$ have type 2 diabetes [1]. The main complications of diabetes-both microvascular (e.g., retinopathy, neuropathy, nephropathy) and macrovascular (e.g., ischemic cardiopathy, peripheral vascular disease, cerebrovascular disease) increase the costs associated, and entail an important reduction in the quantity and the quality of patients' life [2-4].

In recent decades, the improvement in prevention strategies and therapeutic interventions has led to a significant reduction in most diabetes complications. However, this is not so evident in the case of diabetic kidney disease (DKD), which remains the leading cause of end-stage renal disease (ESRD) in Western countries [5,6]. When diabetes induces renal damage, patients have a higher risk of suffering from an endothelial disease in any other territory of the body, and patients with DKD have the highest cardiovascular (CV) risk and mortality among patients with chronic kidney disease (CKD) [7-9]. Therefore, it is essential to focus attention and effort on the early prevention, diagnosis, and treatment of DKD. Despite the high prevalence and increasing incidence of this disease, the underlying pathophysiological mechanisms are not fully understood and, even today, highly sensitive and specific diagnostic tests are not available. In this way, classical biomarkers used to estimate glomerular filtration rate (eGFR) and renal damage-such as serum creatinine and albuminuria-have well-known limitations [10-14], and may fail in the early detection of kidney impairment.

In past years, high-throughput techniques have shown the feasibility of finding new biomarkers of early kidney dysfunction, as well as providing valuable information on the metabolic pathways involved in the physiopathology of DKD and other diabetic microand macrovascular complications [15-24].

The analysis of hundreds of metabolites, protein glycosylation profiles, genetic variants, or emerging biomarkers requires large-sample-size cohorts in order to robustly detect associations. GenoDiabMar is a detailed cohort useful as a tool to improve and expand knowledge on different pathophysiological pathways involved in diabetic complications, and enables the replication of results obtained in different populations to generate collaborative research.

We present the GenoDiabMar registry, created with the aim of providing data on demographic, biochemical, and longitudinal clinical changes in a population of T2D patients attending a real medical outpatient consultation. Moreover, this registry is used to find new emerging biomarkers related to the micro- and macrovascular complications of T2D, with a particular focus on diabetic nephropathy. In this study, we analyzed the clinical and analytical characteristics at baseline and during the almost 5-year follow-up of this population. We assessed whether there were differential risk factors between the sexes in the evolution of renal function, as well as CV events and mortality associated with this population.

\section{Materials and Methods}

\subsection{Study Design}

The GenoDiabMar registry was designed as a prospective study, and has currently collected information regarding 650 Caucasian adults with T2D recruited from the nephrologist consultant of Hospital del Mar and six primary care centers from the Hospital del Mar health area, Litoral-Mar, Barcelona, Spain. The inclusion criteria were adults over 45 years old, diagnosed with T2D at least 10 years before the first study visit, if there was no renal disease-defined as glomerular filtration rate (eGFR) $>60 \mathrm{~mL} / \mathrm{min} / 1.73 \mathrm{~m}^{2}$ and normal 
urine albumin to creatinine ratio $<30 \mathrm{mg} / \mathrm{g}$ ), and if renal damage was present at any time. Additional information is available in the Supplementary Materials).

Between February 2012 and July 2015, 650 T2D patients underwent a basal in-person medical visit (V1) performed by a nephrologist and a nurse. Medical history, demographics, physical examination, and laboratory data were registered along with collection of blood and urine samples. In addition, an annual follow-up of all participants included at the baseline visit was performed in order to obtain complete analytical and clinical parameters, including new cardiovascular events and changes in the status of diabetic retinopathy and nephropathy, as well as mortality, by consulting participants' electronic clinical reports. Between March 2017 and February 2020, living patients with functioning kidneys who did not require renal replacement therapy underwent the second in-person visit (V2). Again, analytical, and clinical data, including changes in treatments, were registered. The second biological samples for the biobank were collected on this second visit, performed an average of $4.7(0.65)$ years from the baseline visit.

\subsection{Data Registry}

\section{Medical Records and CV Risk Factors Assessment}

At the first visit, each participant completed a comprehensive questionnaire about their medical history, including information related to the presence and type of diabetes mellitus in their family history. A complete list of data and samples available at the baseline visit, last visit, and annually during the follow-up are summarized in Figure 1. As depicted, smoking status, history of CV events, hypertension, dyslipidemia, diabetic retinopathy (DR), and medication in use at baseline, along with changes during the follow-up, were recorded. For a detailed definition of how all of the variables were recorded, see the Supplementary Materials.

\subsection{Laboratory Data and Sample Management}

At baseline (V1) and at the last visits (V2), fasting venous blood and urine samples were collected. Serum, urine, DNA, and whole blood samples were stored in freezers of the Nephropathies Research Group (GREN) at the Institut Hospital del Mar d'Investigacions Mèdiques (IMIM) [25] and the Parc de Salut Mar Biobank (MARBiobanc) [26]. All samples for clinical analysis were centralized in a single laboratory-the Catalan Reference Laboratory (LRC). The main variables are summarized in Tables 1 and 2.

Renal function was measured as estimated glomerular filtration rate (eGFR) from calibrated serum creatinine using the Chronic Kidney Disease Epidemiology Collaboration (CKD-EPI) equation [27]. Moderate albuminuria was defined as a urine albumin-tocreatinine ratio (ACR) of 30-299 mg/g, and severe albuminuria was defined as a urine ACR of $300 \mathrm{mg} / \mathrm{g}$ or greater. DKD was defined as eGFR $<60 \mathrm{~mL} / \mathrm{min} / 1.73 \mathrm{~m}^{2}$ and albuminuria $>300 \mathrm{mg} / \mathrm{g}$, or albuminuria 30-299 mg/g and DR, regardless the eGFR. Patients were classified based on their degree of kidney disease following the KDIGO guidelines as grade $1-2$ if eGFR $>90-60 \mathrm{~mL} / \mathrm{min} / 1.73 \mathrm{~m}^{2}$, grade 3 if eGFR $=59-30 \mathrm{~mL} / \mathrm{min} / 1.73 \mathrm{~m}^{2}$, grade 4 if eGFR $=29-15 \mathrm{~mL} / \mathrm{min} / 1.73 \mathrm{~m}^{2}$, and grade 5 if eGFR $<15 \mathrm{~mL} / \mathrm{min} / 1.73 \mathrm{~m}^{2}$ [28].

Novel molecules and biomarkers-Alongside the conventional epidemiological phenotypes assessed by questionnaires, clinical visits, and analytical and medical reports, the GenoDiabMar registry also benefits from high-throughput techniques to assess new biomarkers related to T2D complications.

Metabolomic profiles-Metabolic profiles of 227 metabolic traits, 143 metabolite concentrations, 80 lipid ratios, 3 lipoprotein particle sizes, and a semi-quantitative measure of albumin were determined by Nightingale Health Ltd. (Helsinki, Finland), using a targeted NMR (nuclear magnetic resonance) spectroscopy platform that has been extensively applied for biomarker profiling, as described previously [29-32]. 


\begin{tabular}{|c|c|c|c|}
\hline & $\begin{array}{c}\text { V1. First Visit } \\
2012-2015 \\
\end{array}$ & $\begin{array}{l}\text { Follow-up } \\
\text { (annually) }\end{array}$ & $\begin{array}{l}\text { V2. Last Visit } \\
2017-2020 \\
\end{array}$ \\
\hline \multicolumn{4}{|l|}{ Questionaries } \\
\hline Demographics & $\checkmark$ & & \\
\hline Time of diabetes & $\checkmark$ & & $\checkmark$ \\
\hline \multicolumn{4}{|l|}{ Family history of diabetes } \\
\hline \multicolumn{4}{|l|}{$\begin{array}{l}\text { Cardiovascular risk factors } \\
\text { (Smoke, HBP, DL) }\end{array}$} \\
\hline Cardiovascular events history & $\checkmark$ & $\checkmark$ & $\checkmark$ \\
\hline \multicolumn{4}{|l|}{$\begin{array}{l}\text { Current medication } \\
\text { (anti-hy pertensive, lipid-lowering, anti-diabetics } \\
\text { treatments) }\end{array}$} \\
\hline \multicolumn{4}{|l|}{ Renal replacement therapy } \\
\hline Mortality & & $\checkmark$ & $V$ \\
\hline \multicolumn{4}{|l|}{ Clinical assessments } \\
\hline Anthropometrics (BMI) & $V$ & & $\checkmark$ \\
\hline Blood pressure & $\checkmark$ & & $\checkmark$ \\
\hline Fundoscopy & $\checkmark$ & & $\checkmark$ \\
\hline Abdominal ultrasound & $\checkmark$ & & \\
\hline \multicolumn{4}{|l|}{ Laboratory analysis } \\
\hline Biochemical profile (creatinine, urea, uric acid) & $\checkmark$ & $\checkmark$ & $\checkmark$ \\
\hline Hemogram & $\checkmark$ & & $\checkmark$ \\
\hline \multicolumn{4}{|l|}{$\begin{array}{l}\text { Lipid profile (total cholesterol, LDL, HDL- } \\
\text { cholesterol, triglycerides) }\end{array}$} \\
\hline Albuminuria & $\checkmark$ & $V$ & $V$ \\
\hline $\mathrm{HbA1c}$ & $V$ & $V$ & $\checkmark$ \\
\hline \multicolumn{4}{|l|}{ Special test } \\
\hline \multicolumn{4}{|l|}{ Metabolomic profiles (NMR) } \\
\hline \multicolumn{4}{|l|}{ IgG glycans profiles (UPLC) } \\
\hline \multicolumn{4}{|l|}{ Serum Galectin 3 (ELISA) } \\
\hline \multicolumn{4}{|l|}{ Serum Succinate (fluorometric) } \\
\hline \multicolumn{4}{|l|}{ Available samples } \\
\hline DNA bank and whole blood sample & $V$ & & $V$ \\
\hline Serum samples & $V$ & & $V$ \\
\hline Urine samples & $V$ & & $V$ \\
\hline
\end{tabular}

Figure 1. Summary of available data and samples from different visits and follow-ups: V1: first in-person visit; V2: last in-person visit; HBP: high blood pressure; DL: dyslipidemia; HbA1c: glycosylated hemoglobin; LDL: low-density lipoprotein; HDL: high-density lipoprotein; NMR: nuclear magnetic resonance spectroscopy; UPLC: ultra-performance liquid chromatography.

Immunoglobulin G (IgG) glycan analysis-Variations in IgG's glycan structures influence the effector function of IgG, modulating its immune response as proinflammatory or anti-inflammatory. IgG glycans have been associated with a high variety of conditions, including CKD [23,33].

All of the GenoDiabMar participants had 76 IgG glycan profiles analyzed by ultraperformance liquid chromatography (UPLC) in GENOS Glycoscience Research Laboratory (Zagreb, Croatia).

Other biomarkers available-The cohort also has information on emerging biomarkers of cardiovascular damage, measured in a targeted manner in order to study their role in kidney damage associated with T2D, as well as how they are influenced by kidney function and albuminuria. In this way, we carried out the determination of galectin $3[34,35]$ and succinate [36-39] in a subset of participants. 
DNA banking - To facilitate future genetic studies, all of the participants in the registry underwent DNA extraction from the whole blood sample obtained at the baseline visit. DNA was extracted via an automated method using the QIAsymphony DSP DNA kit for whole blood, in the MARBiobanc facilities.

\section{Results}

\subsection{General Characteristics}

The most relevant clinical characteristics and analytical variables of the cohort are displayed in Tables 1 and 2. A total of 650 participants $-61 \%$ men and 39\% women, aged 69 [14] with a median time of diabetes of 15 [10] years-underwent the first visit. Of those, $356(54.7 \%)$ had diabetic kidney disease at baseline, and the distribution per degree of chronic kidney disease was G1-G2 50.3\%, G3 31.4\%, G4 10.8\%, and G5 7.5\%. Roughly 5 years later (last in-person visit), 442 participants with functioning kidneys completed the follow-up (Table 2). As expected, the presence of DR was significantly more frequent as the glomerular filtration rate worsened, and was present in $25.8 \%$ at baseline and $30.5 \%$ at the last visit. The median body mass index (BMI) was 29.9 [6.8] kg/m². Among the participants, $47.1 \%$ had a history of associated family history of T2D; $18 \%$ of the patients were active smokers, while $37.4 \%$ were ex-smokers. It should be noted that as the degree of CKD worsened, we found a significantly lower percentage of smokers. The prevalence of arterial hypertension (HBP) was high, with $91.4 \%$ of the population being affected and $77.2 \%$ having dyslipidemia. Regarding the history of previous CV events, $20.6 \%$ had a history of ischemic heart disease, with a higher prevalence peak in individuals with grade 4 CKD; $10.5 \%$ had suffered from cerebrovascular disease, and 19.8\% had peripheral vascular disease-both ailments again having a higher prevalence in grade 4 CKD. With respect to antihypertensive treatment, $29.8 \%$ received angiotensin-converting enzyme inhibitors (ACEIs), 40.6\% angiotensin receptor blockers (ARBs), and 2.8\% a combination of ACEIs and ARBs. As detailed in the tables, as glomerular filtration rates worsen, inhibitors of the renin-angiotensin system usage decrease, with a significant drop in grades $4-5$. In addition, $78 \%$ of the participants received calcium channel blockers, beta-blockers, or diuretics; $72.6 \%$ used statins, with a higher prevalence in grade 4 CKD. Concerning antidiabetic drugs, $46.3 \%$ of the participants were taking oral antidiabetic drugs (OADs), 24.3\% insulin, and 28.3\% both treatments combined (OADs and insulin). As detailed in the tables, the use of OADs decreases significantly as the eGFR worsens, with a clear increase in insulin usage, which was the treatment of choice in $79.6 \%$ of patients with grade 5 CKD at the baseline visit. It should be noted that the use of drugs with a demonstrated nephroprotective effect-such as sodium-glucose co-transporter inhibitors (SGLT2i) or glucagon-like peptide-1 receptor agonists (GLP1-RA) —was practically anecdotal at the baseline visit (years 2012-2015); however, we observed a clear trend towards an increase in the prescription of these drugs at the final visit (V2). However, in 2020, the percentage of patients prescribed these drugs was still kept far from the current clinical practice guidelines' recommendations. These data should aware physicians who care for diabetic patients, and prompt them to review the existing biases between the guidelines and real clinical practice $[40,41]$.

Grade 1-2: eGFR > 90-60 mL/min/1.73 $\mathrm{m}^{2}$; grade 3: eGFR = 59-30 mL/min/1.73 $\mathrm{m}^{2}$; grade $4:$ eGFR $=29-15 \mathrm{~mL} / \mathrm{min} / 1.73 \mathrm{~m}^{2}$; grade $5:$ eGFR $<15 \mathrm{~mL} / \mathrm{min} / 1.73 \mathrm{~m}^{2}$. CKD: chronic kidney disease; BMI: body mass index; HBP: high blood pressure; ACEI/ARB: angiotensin-converting enzyme (ACE) inhibitor/angiotensin II receptor blocker; iDPP4: inhibitors of dipeptidyl peptidase 4 SGLT2i: sodium-glucose co-transporter inhibitor; GLP1-RA: glucagon-like peptide-1 receptor agonist; HbA1c: glycosylated hemoglobin; LDL: low-density lipoprotein; HDL: high-density lipoprotein. Quantitative data are expressed as medians (interquartile ranges), while qualitative variables are given in absolute and relative frequencies; $p$-values $<0.05$ indicate that there are statistically significant differences between groups in the multiple comparison tests. 
Table 1. General characteristics at baseline visits by grades of chronic kidney disease.

\begin{tabular}{|c|c|c|c|c|c|}
\hline CKD Grade & $1-2$ & 3 & 4 & 5 & $p$ \\
\hline $\mathrm{N}$ & 327 & 204 & 70 & 49 & \\
\hline Age (years) & $67(10)$ & $75(13)$ & $76(10)$ & $81(22)$ & $<0.001$ \\
\hline Time of diabetes (years) & $14(10)$ & $15(10)$ & $17(12)$ & $14(4)$ & $<0.001$ \\
\hline Gender (Male/Female) (\%) & $61.8 / 38.2$ & $61.6 / 38.2$ & $55.7 / 44.3$ & $61.3 / 38.8$ & 0.812 \\
\hline BMI $\left(\mathrm{kg} / \mathrm{m}^{2}\right)$ & $29.7(6.8)$ & $30.5(6.6)$ & $30.3(7.6)$ & $23.4(4)$ & 0.045 \\
\hline Smokers/former smokers (\%) & $24.8 / 34.5$ & $15.2 / 39.2$ & $4.3 / 45.7$ & $4.1 / 36.7$ & $<0.001$ \\
\hline HBP (\%) & 69.4 & 98.5 & 95.7 & 100 & $<0.001$ \\
\hline $\begin{array}{l}\text { Antihypertensive treatment } \\
\mathrm{ACEi} / \mathrm{ARB} / \mathrm{ACEi}+\mathrm{ARB} \%\end{array}$ & $32.7 / 39.7 / 3.1$ & $35.3 / 45.6 / 2.9$ & $11.4 / 41.4 / 5.7$ & $14.3 / 49 / 0$ & $<0.001$ \\
\hline Cardiovascular events history (\%) & 31.5 & 46.1 & 60 & 48.9 & $<0.001$ \\
\hline Ischemic cardiomyopathy & 12.8 & 26.5 & 34.3 & 28.6 & $<0.001$ \\
\hline Cerebrovascular disease & 9.5 & 11.3 & 37.1 & 10.2 & 0.822 \\
\hline Peripheral vascular disease & 14.7 & 23 & 12.9 & 22.5 & 0.019 \\
\hline Diabetic retinopathy (\%) & 17.1 & 27.9 & 34.3 & 63.3 & $<0.001$ \\
\hline Lipid-lowering therapy (statin \%) & 71.8 & 80.9 & 85.7 & 85.7 & 0.002 \\
\hline \multicolumn{6}{|l|}{ Antidiabetic treatment (\%) } \\
\hline Oral agents/insulin/combined & $59.3 / 6.1 / 33.9$ & $43.1 / 28.4 / 26.9$ & $7.3 / 58.6 / 20$ & $8.1 / 79.6 / 6.1$ & $<0.001$ \\
\hline iDPP4/SGLT2i/GLP1-RA & $7.6 / 0.3 / 0.9$ & $1.9 / 0.5 / 0.5$ & $1.4 / 0 / 0$ & $0 / 0 / 0$ & 0.808 \\
\hline eGFR (mL/min $\left.71.73 \mathrm{~m}^{2}\right)$ & $82.2(24.1)$ & $42.8(13.2)$ & $23.5(19.6)$ & $9.14(3.75)$ & $<0.001$ \\
\hline Urinary albumin/creatinine (mg/g) & $9.5(53.3)$ & $85.8(434)$ & $465(1574.7)$ & $1158(3210.8)$ & $<0.001$ \\
\hline $\mathrm{HbA} 1 \mathrm{c}(\mathrm{mmol} / \mathrm{mol})$ & $60.1(17.9)$ & $60.6(19.6)$ & $59.1(19.6)$ & $53(13)$ & 0.004 \\
\hline \multicolumn{6}{|l|}{ Cholesterol (mg/dL) } \\
\hline Total & $173(45)$ & $165(49)$ & $165.5(54)$ & $143(42)$ & $<0.001$ \\
\hline LDL & $96(36.5)$ & $87(36)$ & $91(42)$ & $71(35)$ & $<0.001$ \\
\hline HDL & $45(14)$ & $45.2(19)$ & $42(19)$ & $43(13)$ & 0.665 \\
\hline Triglycerides (mg/dL) & $129(91.7)$ & $144(86)$ & 141 (93) & $125(60)$ & 0.072 \\
\hline Uric acid (mg/dL) & $5.4(1.9)$ & $6.6(1.7)$ & $7(1.9)$ & $6(0.8)$ & $<0.001$ \\
\hline Hemoglobin (mg/dL) & $13.6(2.1)$ & $12.6(1.88)$ & $11.5(1.45)$ & $12.1(2)$ & $<0.001$ \\
\hline
\end{tabular}

Table 2. General characteristics at baseline visits and at the end of follow-up visits.

\begin{tabular}{|c|c|c|}
\hline & $\begin{array}{l}\text { First Visit } \\
2012-2015\end{array}$ & $\begin{array}{l}\text { Last Visit } \\
2017-2020\end{array}$ \\
\hline $\mathrm{N}$ & 650 & 442 \\
\hline Age (years) & $69(14)$ & $72.9(13)$ \\
\hline Sex (male/female \%) & $61.1 / 38.9$ & $61.5 / 38.8$ \\
\hline $\mathrm{BMI}\left(\mathrm{kg} / \mathrm{m}^{2}\right)$ & $29.9(6.8)$ & $29.2(6.2)$ \\
\hline Family history of diabetes (\%) & 47.1 & 53.1 \\
\hline Cardiovascular risk factors history & & \\
\hline
\end{tabular}


Table 2. Cont.

\begin{tabular}{|c|c|c|}
\hline & $\begin{array}{l}\text { First Visit } \\
2012-2015\end{array}$ & $\begin{array}{l}\text { Last Visit } \\
2017-2020\end{array}$ \\
\hline Smokers / former smoker (\%) & $18 / 37.4$ & $15.8 / 41.4$ \\
\hline High blood pressure (\%) & 91.4 & 90.9 \\
\hline Dyslipidemia (\%) & 77.2 & 73 \\
\hline Cardiovascular events history (\%) & 40.5 & 41.17 \\
\hline Myocardial infarction (\%) & 20.6 & 21.3 \\
\hline Cerebrovascular disease (\%) & 10.5 & 14.3 \\
\hline Peripheral vascular disease (\%) & 19.8 & 20.4 \\
\hline Diabetic retinopathy (\%) & 25.8 & 30.5 \\
\hline $\begin{array}{c}\text { Antihypertensive treatment } \\
\text { ACEI/ARB/ACEI + ARB (\%) }\end{array}$ & $29.8 / 40.6 / 2.8$ & $31 / 37.8 / 2.3$ \\
\hline $\begin{array}{c}\text { Others } \\
\text { (Calcium antagonists/ß-blockers/diuretics) (\%) }\end{array}$ & 78 & 80.8 \\
\hline \multicolumn{3}{|l|}{ Lipid-lowering therapy (\%) } \\
\hline Statins & 72.6 & 68.1 \\
\hline Fibrates & 10.1 & 6.8 \\
\hline Other & 3.4 & 7.8 \\
\hline \multicolumn{3}{|l|}{ Antidiabetic treatment } \\
\hline Oral agents only (\%) & 46.3 & 41.2 \\
\hline DPP4i/SGLT2i/GLP1-RA (\%) & $6.1 / 0.3 / 0.6$ & $21 / 5.9 / 4.3$ \\
\hline Insulin only $(\%)$ & 24.3 & 21 \\
\hline Oral agents + insulin (\%) & 28.3 & 34.6 \\
\hline $\operatorname{Diet}(\%)$ & 1.1 & 1.1 \\
\hline Serum creatinine $(\mathrm{mg} / \mathrm{dL})$ & $1.12(0.81)$ & $1.11(0.78)$ \\
\hline eGFR (mL/min/1.73mt2) & $60.4(46.5)$ & $57.7(46.4)$ \\
\hline Urinary albumin/creatinine $(\mathrm{mg} / \mathrm{g})$ & $34.2(217.05)$ & $32.6(219.9)$ \\
\hline Hemoglobin (gr/dL) & $13(2.2)$ & $13.1(2.5)$ \\
\hline $\mathrm{HbA1c}(\mathrm{mmol} / \mathrm{mol})$ & $59.6(18.5)$ & $55.2(18.5)$ \\
\hline Uric acid $(\mathrm{mg} / \mathrm{dL})$ & $6.1(2.1)$ & $6.6(2.5)$ \\
\hline Total cholesterol (mg/dL) & $171(48)$ & $162(57)$ \\
\hline LDL cholesterol (mg/dL) & $94(39)$ & $89(44)$ \\
\hline HDL cholesterol (mg/dL) & $45(16)$ & $46(17)$ \\
\hline Triglycerides (mg/dL) & $136(90)$ & $137(90.5)$ \\
\hline
\end{tabular}

BMI: body mass index; ACEI/ARB: angiotensin-converting enzyme (ACE) inhibitors/angiotensin II receptor blockers; iDPP4: inhibitors of dipeptidyl peptidase 4; SGLT2i: sodium-glucose co-transporter inhibitors; GLP1RA: glucagon-like peptide-1 receptor agonists; eGFR: estimated glomerular filtration rate; $\mathrm{HbA1c}$ : glycosylated hemoglobin; LDL: low-density lipoprotein; HDL: high-density lipoprotein. The median time between the first in-person visit and the last was $4.7(0.65)$ years. Quantitative data are expressed as medians [interquartile ranges] while qualitative variables are given in absolute and relative frequencies. Losses due to mortality between the two visits were 137 patients.

\subsection{Patient Follow-Up: Renal Deterioration by Sex and Mortality}

To attain a longitudinal view of the proceeding of the main variables of the cohort, we assessed the evolution of renal function in the 611 participants with functioning kidneys at the baseline visit (non-dialysis patients). The overall mean annual glomerular filtration loss was $-1.2\left(-1.8:-0.5 \mathrm{~mL} / \mathrm{min} / 1.73 \mathrm{~m}^{2}\right)$, being different between men and women. 
Men had a median eGFR higher than women at baseline (66.3 [41.8:84.3] vs. 63.4 [41.7:86.4] $\left.\mathrm{mL} / \mathrm{min} / 1.73 \mathrm{~m}^{2}\right)$, but the rate of loss of kidney function was significantly lower in women, losing 0.93 (0.40-1.46) fewer glomerular filtration units per year than men, regardless of albuminuria (Figure 2). Roughly $17 \%$ of the patients experienced rapid deterioration of renal function-defined as a loss of $\geq 5 \mathrm{~mL} / \mathrm{min} / 1.73 \mathrm{~m}^{2} /$ year [28] over the follow-up period-of whom $75.2 \%$ were men and $24.7 \%$ were women.

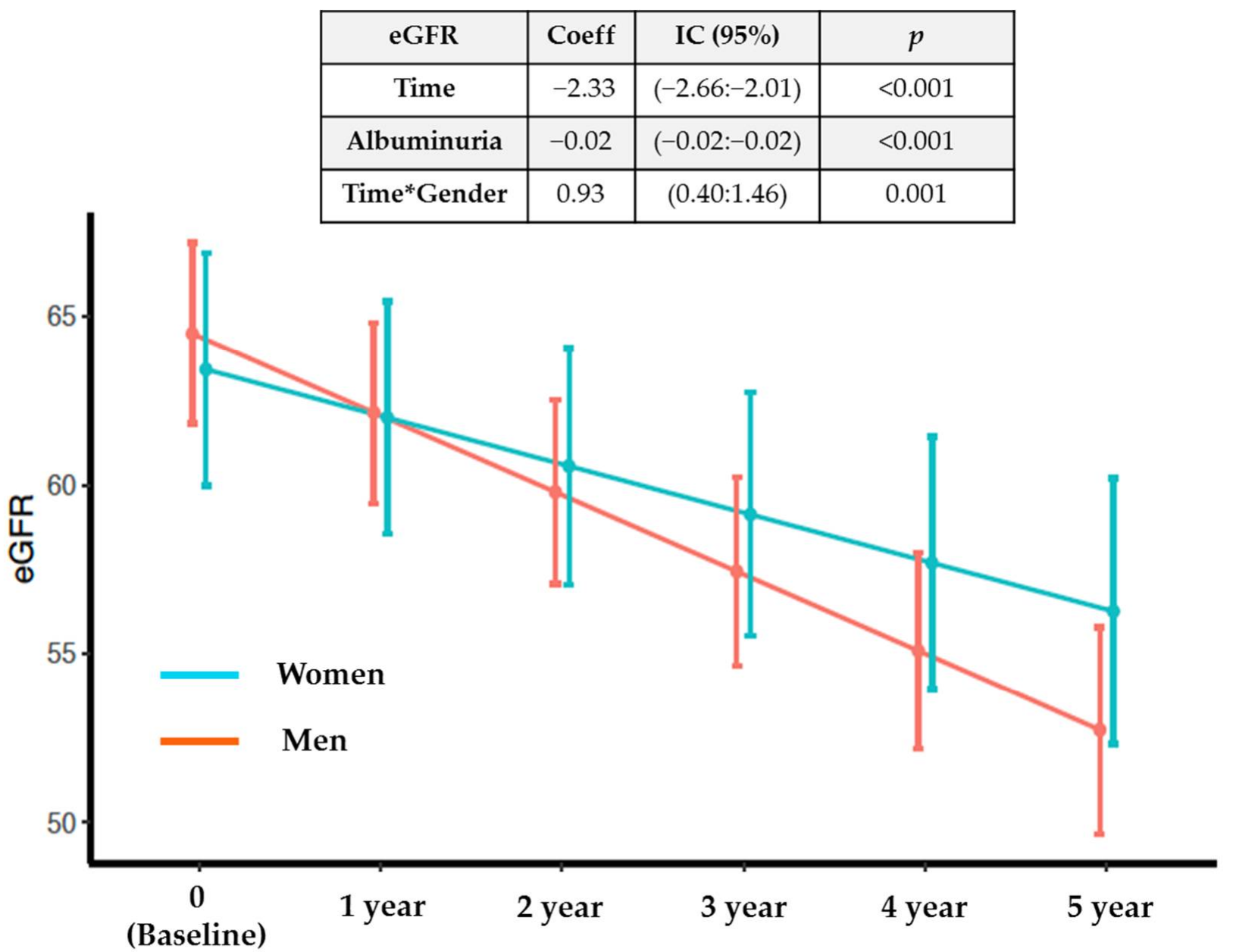

Time

Figure 2. Evolution of estimated glomerular filtration rate (eGFR) by sex, adjusted by albuminuria, Time and Gender interaction (Time ${ }^{*}$ Gender) in the mixed linear model, and its graphical representation of the mean eGFR between sexes.

The parameters influencing a faster deterioration of renal function were different between the sexes. As depicted in Table 3, the presence of peripheral vascular disease was a risk factor for women, but not for men. Additionally, macroalbuminuria was a significant factor for men, but not for women. The area under the ROC curve (AUC) for predicting rapid progression based on albuminuria was 0.62 [0.55:0.68] with a cutoff value of $451 \mathrm{mg} / \mathrm{g}$ for men, and 0.70 [0.62-0.78] with a cutoff value of $18.4 \mathrm{mg} / \mathrm{g}$ for women. These findings can help to identify early clinical and analytical risk factors for worse renal evolution in a differential and more personalized manner. 
Table 3. Risk factors for rapid deterioration of kidney function by sex.

\begin{tabular}{ccccc}
\hline & Men & \multicolumn{2}{c}{ Women } \\
\hline & OR (IC95\%) & $p$ & OR (IC95\%) & $p$ \\
\hline Age & $1.01(0.98: 1.04)$ & 0.62 & $1.02(0.97: 1.08)$ & 0.48 \\
\hline Diabetic retinopathy & $1.18(0.61: 2.23)$ & 0.61 & $0.99(0.25: 3.33)$ & 0.98 \\
\hline Time of DM2 & $1.02(0.99: 1.06)$ & 0.18 & $0.97(0.91: 1.03)$ & 0.42 \\
\hline BMI & $1.03(0.96: 1.10)$ & 0.45 & $0.97(0.89: 1.05)$ & 0.47 \\
\hline Ischemic cardiopathy & $1.02(0.53: 1.88)$ & 0.94 & $1.16(0.31: 3.39)$ & 0.80 \\
\hline Peripheral vascular disease & $0.79(0.39: 1.53)$ & 0.49 & $3.32(1.10: 9.57)$ & 0.02 \\
\hline Stroke & $1.83(0.85: 3.74)$ & 0.12 & $1.82(0.38: 6.21)$ & 0.41 \\
\hline Albuminuria $>$ 300 mg/g & $2.40(1.29: 4.44)$ & 0.005 & $0.99(0.91: 3.73)$ & 0.99 \\
\hline HbA1c & $0.89(0.71: 1.11)$ & 0.32 & $1.14(0.80: 1.59)$ & 0.43 \\
\hline Smoker & $1.03(0.46: 2.30)$ & 0.94 & $1.15(0.21: 4.97)$ & 0.86 \\
\hline Former smoker & $0.72(0.37: 1.46)$ & 0.35 & $0.29(0.02: 1.62)$ & 0.25 \\
\hline
\end{tabular}

Multivariate logistic regression model showing the variables of risk of undergoing a rapid decline in renal function, defined as a loss of $>5 \mathrm{ml} / \mathrm{min} / \mathrm{m}^{2}$ in estimated glomerular filtration rate (eGFR) per year, separated by sex.

Although this registry was initially started with the objective of studying new biomarkers of kidney injury in T2D, it is a well-characterized population that has detailed information on other micro- and macrovascular diabetic complications, which we also analyzed. Thus, during the follow-up period, 135 patients (22.1\%) endured one or more CV events, of whom $33.3 \%$ fulfilled the established criteria for DKD and $18.4 \%$ did not match the DKD criteria at baseline $(p<0.001)$. Figure $3 \mathrm{~A}$ shows the schematic distribution of the new onset of CV events and DR. During the follow-up, 137 patients (22.4\%) developed DR or worsened their previously established DR. In addition, $75(12.4 \%), 54(8.4 \%)$, and $28(4.38 \%)$ patients developed or worsened ischemic cardiopathy, peripheral vascular disease, and cerebrovascular disease, respectively. A higher incidence of events was observed in the group of patients who met the criteria for established DKD at the baseline visit (Figure 3B).

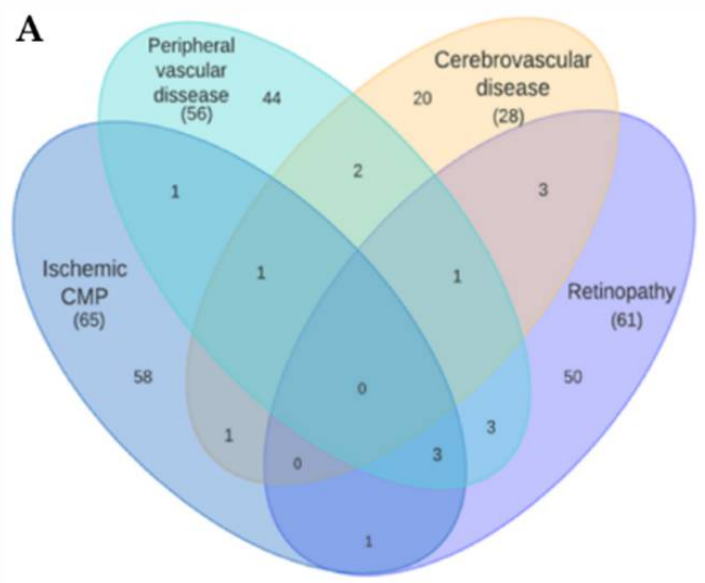

B

\begin{tabular}{|l|c|c|l|}
\hline Incidence, $\%(n$-case $/ n$-total $)$ & $\begin{array}{c}\text { No criteria of DKD } \\
\text { at baseline visit }\end{array}$ & $\begin{array}{c}\text { DKD criteria } \\
\text { at baseline visit }\end{array}$ & \\
\hline$n$ & 294 & 356 & $p$ \\
\hline Ischemic cardiomyopathy & $23(7.9 \%)$ & $52(16.5 \%)$ & $<0.001$ \\
Peripheral vascular disease & $24(8.1 \%)$ & $32(8.9 \%)$ & 0.85 \\
Cerebrovascular disease & $9(3.06 \%)$ & $19(5.3 \%)$ & $<0.05$ \\
\hline Diabetic Retinopathy & $47(16.2 \%)$ & $90(28.7 \%)$ & $<0.001$ \\
\hline
\end{tabular}

Figure 3. (A) Schematic distribution of the recorded cardiovascular events and new onset of diabetic retinopathy, throughout the follow-up period; (B) Incidence of the recorded cardiovascular events and diabetic retinopathy during the follow-up, by criteria of DKD at baseline visit.

There was overall mortality of $23 \%-38 \%$ of which was due to cardiovascular causes, and $16 \%$ due to cancer. Furthermore, throughout the follow-up, 22 patients (3.6\%) started 
renal replacement therapy, and 10 were lost to follow-up (Figures 4 and S1: Flow-diagram of patients recruitment and follow up).
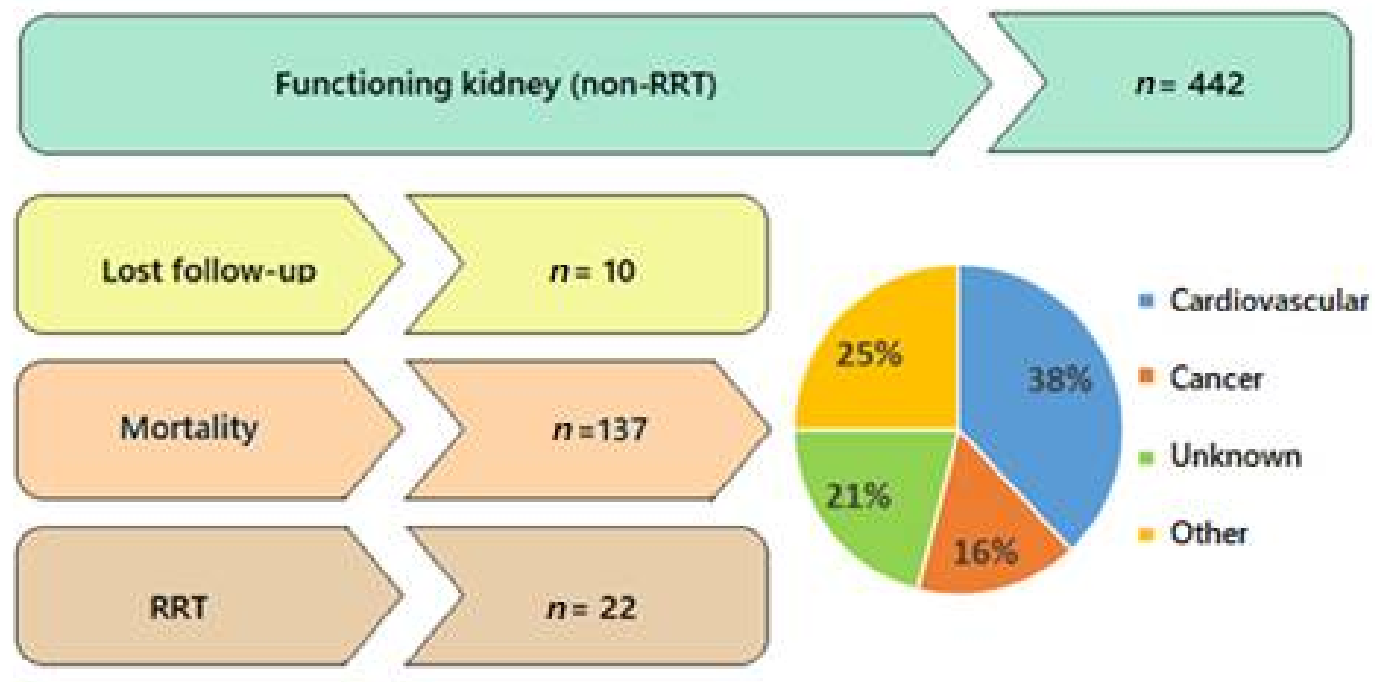

Figure 4. Flowchart depicting patients' distribution during follow-up, their need for renal replacement therapy (RRT), mortality, and its causes. Pie chart shows causes of mortality distributed in percentages.

\section{Discussion}

This is a well-characterized registry with information on longitudinal micro- and macrovascular complications of T2D, as well as detailed clinical and analytical information. We have provided a detailed picture of the clinical and analytical behavior of these patients, so as to facilitate detailed knowledge of the available variables, as well as their distribution and evolution. In this way, the data of this registry are closer to "real-world data" (RWD), with patients who sometimes may be excluded from other types of clinical trials or studies, with strict inclusion criteria. This allows us to obtain evidence that is closer to routine clinical practice.

The characteristics of the evolution of renal function and the differences found between the sexes in morbimortality are similar to those described in the literature [42-44] for DKD patients. This observation reinforces the value of this registry as a population, with renal characteristics comparable to other cohorts, so as to be able to carry out collaborative studies. It is worth noting that the risk factors of rapid deterioration of renal function, which differ between sexes, are clinical and analytical factors available in any medical consultation. This is of special value in evaluating the patient's risk in an individualized manner during routine consultation.

The absolute value of macrovascular events is not high compared to other largepopulation cohorts. However, since this cohort has patients with a high burden of disease, recruited from real consultations-which allows us a more reliable and closer follow-up of the clinical events-the relative values and percentages of events and complications are similar to or even higher than those observed in other, larger cohorts. As stated, it is important to join efforts in conducting collaborative studies to minimize statistical power problems and, although a single registry may not have enough events, management through metaanalysis of results and validation of data in external cohorts is postulated as a mandatory scientific practice. In this study, we have shown that diabetic patients with kidney disease, beyond classic antihypertensive or lipid-lowering treatments and acceptable metabolic control, have a very high mortality - mainly associated with cardiovascular events. The 
physicians attending this kind of patient-general practitioners, endocrinologists, cardiologists, or nephrologists-must be especially aware and approach these patients in a multidisciplinary manner. The low percentage of patients in this cohort under treatment with drugs that have demonstrated cardio- and nephroprotection (SGLT2i or GLP1-AR) is remarkable. Although we know that this trend is changing, we must continue efforts to implement these drugs in routine clinical practice.

In addition, the main strengths of this cohort are that it includes a collection of baseline and longitudinal follow-up biological samples, and covers the entire spectrum of kidney disease, including patients from grade 1 CKD to patients on renal replacement therapy. As these are patients from medical consultations belonging to our healthcare area, we have detailed and precise information about them, and we can ensure good monitoring capacity.

One of the limitations of the study is the generalizability of the findings, which is limited to Caucasian subjects. The results of our study may be validated in multiethnic cohorts in order to evaluate their applicability in broader populations with T2D. We do not have urine samples from all of the participants, and lack information regarding diet and lifestyle. Moreover, we have not conducted kidney histological studies in most of the patients to ensure the renal disease etiology. Since no other reliable and non-invasive markers have been established, we cannot overcome this limitation but, in order to minimize misdiagnosis, medical history-including ultrasonography and fundoscopy studies-was reviewed by two nephrologists. In addition, to date, the registry has only ensured the extraction of DNA from the samples, but they have not yet been sequenced. With current technology, the statistical power of the cohort would be insufficient to propose GWAS-type studies without a prior hypothesis. However, once the population has been sequenced, studies aimed at validating predetermined genetic variants could be considered, as well as potential replication studies.

We presented a registry of patients from real nephrology and primary care medical outpatient consultations, from which we have registered several clinical and analytical variables for 5 years. In addition, the registry includes serum and urine biobanks, DNA banks, and data on metabolomics, glycomics, and other biomarkers already analyzed. We consider this cohort to be a great potential tool for scientific collaboration for studies, whether they are focused on T2D, or whether they are interested in comparing differential markers between diabetic and non-diabetic populations. Furthermore, as we have shown in other collaborative projects, the GenoDiabMar registry can meet the criteria to replicate or meta-analyze results obtained in other cohorts. It should be noted that this registry is part of The Consortium of Metabolomics Studies (COMETS), whose main objective is to create a collaborative network to identify metabolomic markers associated with different phenotypes and pathologies [45].

This descriptive publication of our GenoDiabMar registry should engage researchers in collaborative efforts to advance knowledge of the etiology, diagnosis, treatment, and prognosis of T2D complications. In this spirit, we invite researchers-including those without data of their own-to join us with scientific collaboration proposals.

Supplementary Materials: The following supporting information can be downloaded at: https: / /www.mdpi.com/article/10.3390/jcm11051431/s1, Supplementary Material and Methods; Figure S1: Flow-diagram of patients recruitment and follow up. References $[46,47]$ are cited in the Supplementary Materials.

Author Contributions: Conceptualization, C.B.; methodology, A.S., S.O., A.F., M.V., J.F.-N. and X.M., validation, C.B. and J.P.; formal analysis, A.S., S.O., X.D., A.C.-G. and C.B.; investigation, A.S., E.R., E.M. and C.B.; resources and funding acquisition, J.P., M.C. and C.B.; data curation, A.S., S.O., X.D., A.C.-G. and C.B.; writing-original draft preparation, A.S., S.O. and C.B.; writing-review and editing, all authors; supervision, C.B. All authors have read and agreed to the published version of the manuscript. 
Funding: Clara Barrios was funded by the grant FIS-FEDER-ISCIII PI16/00620 (Ext 2021) and the Strategic Plan for Research and Innovation in Health, CatSalut, PERIS STL008 (2019-2021) to develop clinical and epidemiological studies mainly focused on diabetes and its associations with new biomarkers.

Institutional Review Board Statement: The study was conducted in accordance with the Declaration of Helsinki, and approved by the Ethics Committee of CEIm-Parc de Salut Mar protocol number 2019/8459/I. Latest update 21 June 2019.

Informed Consent Statement: Informed consent was obtained from all subjects involved in the study.

Conflicts of Interest: The authors declare no conflict of interest. The funders had no role in the design of the study; in the collection, analyses, or interpretation of data; in the writing of the manuscript, or in the decision to publish the results.

\section{References}

1. Khan, M.A.B.; Hashim, M.J.; King, J.K.; Govender, R.D.; Mustafa, H.; Al Kaabi, J. Epidemiology of Type 2 Diabetes-Global Burden of Disease and Forecasted Trends. J. Epidemiol. Glob. Health 2020, 10, 107-111. [CrossRef] [PubMed]

2. Einarson, T.R.; Acs, A.; Ludwig, C.; Panton, U.H. Economic Burden of Cardiovascular Disease in Type 2 Diabetes: A Systematic Review. Value Health 2018, 21, 881-890. [CrossRef] [PubMed]

3. Speight, J.; Holmes-Truscott, E.; Hendrieckx, C.; Skovlund, S.; Cooke, D. Assessing the impact of diabetes on quality of life: What have the past 25 years taught us? Diabet. Med. 2019, 37, 483-492. [CrossRef] [PubMed]

4. Preston, S.H.; Choi, D.; Elo, I.T.; Stokes, A. Effect of diabetes on life expectancy in the United States by race and ethnicity. Biodemogr. Soc. Biol. 2018, 64, 139-151. [CrossRef]

5. Navaneethan, S.D.; Schold, J.D.; Jolly, S.E.; Arrigain, S.; Winkelmayer, W.C.; Nally, J.V. Diabetes Control and the Risks of ESRD and Mortality in Patients With CKD. Am. J. Kidney Dis. 2017, 70, 191-198. [CrossRef]

6. $\quad$ Gregg, E.; Li, Y.; Wang, J.; Burrows, N.R.; Ali, M.K.; Rolka, D.; Williams, D.E.; Geiss, L. Changes in Diabetes-Related Complications in the United States, 1990-2010. N. Engl. J. Med. 2014, 370, 1514-1523. [CrossRef]

7. Tancredi, M.; Rosengren, A.; Svensson, A.-M.; Kosiborod, M.; Pivodic, A.; Gudbjörnsdottir, S.; Wedel, H.; Clements, M.; Dahlqvist, S.; Lind, M. Excess Mortality among Persons with Type 2 Diabetes. N. Engl. J. Med. 2015, 373, 1720-1732. [CrossRef]

8. Tonelli, M.; Muntner, P.; Lloyd, A.; Manns, B.J.; Klarenbach, S.; Pannu, N.; James, M.T.; Hemmelgarn, B.R. Risk of coronary events in people with chronic kidney disease compared with those with diabetes: A population-level cohort study. Lancet 2012, 380, 807-814. [CrossRef]

9. Barrios, C.; Pascual, J.; Otero, S.; Soler, M.J.; Rodríguez, E.; Collado, S.; Faura, A.; Mojal, S.; Navarro-González, J.; Betriu, A.; et al. Diabetic nephropathy is an independent factor associated to severe subclinical atheromatous disease. Atherosclerosis 2015, 242, 37-44. [CrossRef]

10. Levey, A.S.; Becker, C.; Inker, L.A. Glomerular filtration rate and albuminuria for detection and staging of acute and chronic kidney disease in adults: A systematic review. JAMA J. Am. Med. Assoc. 2015, 313, 837-846. [CrossRef]

11. Inker, L.A.; Schmid, C.H.; Tighiouart, H.; Eckfeldt, J.H.; Feldman, H.I.; Greene, T.; Kusek, J.W.; Manzi, J.; Van Lente, F.; Zhang, Y.L.; et al. Estimating Glomerular Filtration Rate from Serum Creatinine and Cystatin, C. N. Engl. J. Med. 2012, 367, 20-29. [CrossRef] [PubMed]

12. Stevens, L.A.; Coresh, J.; Greene, T.; Levey, A.S. Assessing Kidney Function-Measured and Estimated Glomerular Filtration Rate. N. Engl. J. Med. 2006, 354, 2473-2483. [CrossRef] [PubMed]

13. Krolewski, A.S.; Niewczas, M.A.; Skupien, J.; Gohda, T.; Smiles, A.; Eckfeldt, J.H.; Doria, A.; Warram, J.H. Early Progressive Renal Decline Precedes the Onset of Microalbuminuria and Its Progression to Macroalbuminuria. Diabetes Care 2013, 37, $226-234$. [CrossRef] [PubMed]

14. Ferguson, T.W.; Komenda, P.; Tangri, N. Cystatin C as a biomarker for estimating glomerular filtration rate. Curr. Opin. Nephrol. Hypertens. 2015, 24, 295-300. [CrossRef]

15. Jha, J.C.; Jandeleit-Dahm, K.A.; Cooper, M.E. New Insights into the Use of Biomarkers of Diabetic Nephropathy. Adv. Chronic Kidney Dis. 2014, 21, 318-326. [CrossRef]

16. Zhang, Y.; Zhang, S.; Wang, G. Metabolomic biomarkers in diabetic kidney diseases-A systematic review. J. Diabetes Complicat. 2015, 29, 1345-1351. [CrossRef]

17. Barrios, C.; Spector, T.D.; Menni, C. Blood, urine and faecal metabolite profiles in the study of adult renal disease. Arch. Biochem. Biophys. 2015, 589, 81-92. [CrossRef]

18. Sekula, P.; Goek, O.-N.; Quaye, L.; Barrios, C.; Levey, A.S.; Römisch-Margl, W.; Menni, C.; Yet, I.; Gieger, C.; Inker, L.A.; et al. A Metabolome-Wide Association Study of Kidney Function and Disease in the General Population. J. Am. Soc. Nephrol. 2015, 27, 1175-1188. [CrossRef]

19. Barrios, C.; Beaumont, M.; Pallister, T.; Villar, J.; Goodrich, J.K.; Clark, A.; Pascual, J.; Ley, R.; Spector, T.D.; Bell, J.; et al. Gut-Microbiota-Metabolite Axis in Early Renal Function Decline. PLoS ONE 2015, 10, e0134311. [CrossRef] 
20. Rysz, J.; Gluba-Brzózka, A.; Franczyk, B.; Jabłonowski, Z.; Ciałkowska-Rysz, A. Novel Biomarkers in the Diagnosis of Chronic Kidney Disease and the Prediction of Its Outcome. Int. J. Mol. Sci. 2017, 18, 1702. [CrossRef]

21. Colhoun, H.M.; Marcovecchio, M.L. Biomarkers of diabetic kidney disease. Diabetologia 2018, 61, 996-1011. [CrossRef] [PubMed]

22. Barrios, C.; Zierer, J.; Würtz, P.; Haller, T.; Metspalu, A.; Gieger, C.; Thorand, B.; Meisinger, C.; Waldenberger, M.; Raitakari, O.; et al. Circulating metabolic biomarkers of renal function in diabetic and non-diabetic populations. Sci. Rep. 2018, 8, 15249. [CrossRef]

23. Barrios, C.; Zierer, J.; Gudelj, I.; Štambuk, J.; Ugrina, I.; Rodríguez, E.; Soler, M.J.; Pavić, T.; Šimurina, M.; Keser, T.; et al Glycosylation Profile of IgG in Moderate Kidney Dysfunction. J. Am. Soc. Nephrol. 2015, 27, 933-941. [CrossRef] [PubMed]

24. Dubin, R.F.; Rhee, E.P. Proteomics and Metabolomics in Kidney Disease, including Insights into Etiology, Treatment, and Prevention. Clin. J. Am. Soc. Nephrol. 2019, 15, 404-411. [CrossRef] [PubMed]

25. Kidney Disease-IMIM Institut Hospital del Mar d'Investigacions Mèdiques. Available online: https://www.imim.es/ programesrecerca/rct/en_nefropaties.html (accessed on 19 December 2021).

26. Parc de Salut Mar's Biobank. Hospital del Mar Medical Research Institute. IMIM. Available online: https://www.imim.es/sct/ biobanc/en_index.html (accessed on 19 December 2021).

27. Levey, A.S.; Stevens, L.A.; Schmid, C.H.; Zhang, Y.L.; Castro, A.F., III; Feldman, H.I.; Kusek, J.W.; Eggers, P.; Van Lente, F.; Greene, T.; et al. A New Equation to Estimate Glomerular Filtration Rate. Ann. Intern. Med. 2009, 150, 604-612. [CrossRef]

28. Levin, A.; Stevens, P.E.; Bilous, R.W.; Coresh, J.; De Francisco, A.L.M.; De Jong, P.E.; Griffith, K.E.; Hemmelgarn, B.R.; Iseki, K.; Lamb, E.J.; et al. Kidney disease: Improving global outcomes (KDIGO) CKD work group. KDIGO 2012 clinical practice guideline for the evaluation and management of chronic kidney disease. Kidney Int. Suppl. 2013, 3, 1-150. [CrossRef]

29. Beckonert, O.; Keun, H.C.; Ebbels, T.M.D.; Bundy, J.; Holmes, E.; Lindon, J.C.; Nicholson, J.K. Metabolic profiling, metabolomic and metabonomic procedures for NMR spectroscopy of urine, plasma, serum and tissue extracts. Nat. Protoc. 2007, 2, 2692-2703. [CrossRef]

30. Fischer, K.; Kettunen, J.; Würtz, P.; Haller, T.; Havulinna, A.S.; Kangas, A.; Soininen, P.; Esko, T.; Tammesoo, M.-L.; Mägi, R.; et al Biomarker Profiling by Nuclear Magnetic Resonance Spectroscopy for the Prediction of All-Cause Mortality: An Observational Study of 17,345 Persons. PLOS Med. 2014, 11, e1001606. [CrossRef]

31. Grinde, M.T.; Giskeødegård, G.F.; Andreassen, T.; Tessem, M.-B.; Bathen, T.F.; Moestue, S.A. Biomarker Discovery Using NMR-Based Metabolomics of Tissue. Methods Mol. Biol. 2019, 2037, 243-262. [CrossRef]

32. Silva, R.A.; Pereira, T.C.; Souza, A.R.; Ribeiro, P.R. 1H NMR-based metabolite profiling for biomarker identification. Clin. Chim. Acta 2019, 502, 269-279. [CrossRef]

33. Wang, T.T. IgG FC Glycosylation in Human Immunity. In Current Topics in Microbiology and Immunology; Springer: Berlin, Germany, 2019.

34. Hodeib, H.; Hagras, M.M.; Abdelhai, D.; Watany, M.M.; Selim, A.; Tawfik, M.A.; Elsebaey, M.A.; Elshweikh, S.A. Galectin-3 as a prognostic biomarker for diabetic nephropathy. Diabetes Metab. Syndr. Obes. Targets Ther. 2019, 12, 325-331. [CrossRef] [PubMed]

35. Hussain, S.; Habib, A.; Hussain, S.; Najmi, A.K. Potential biomarkers for early detection of diabetic kidney disease. Diabetes Res. Clin. Pract. 2020, 161, 108082. [CrossRef] [PubMed]

36. Yang, L.; Yu, D.; Mo, R.; Zhang, J.; Hua, H.; Hu, L.; Feng, Y.; Wang, S.; Zhang, W.-Y.; Yin, N.; et al. The Succinate Receptor GPR91 Is Involved in Pressure Overload-Induced Ventricular Hypertrophy. PLoS ONE 2016, 11, e0147597. [CrossRef] [PubMed]

37. Andrienko, T.N.; Pasdois, P.; Pereira, G.; Ovens, M.J.; Halestrap, A.P. The role of succinate and ROS in reperfusion injury-A critical appraisal. J. Mol. Cell. Cardiol. 2017, 110, 1-14. [CrossRef] [PubMed]

38. Mallafré, V.C.; Llauradó, G.; Keiran, N.; Benaiges, E.; Astiarraga, B.; Martínez, L.; Pellitero, S.; González-Clemente, J.M.; Rodríguez, A.; Fernández-Real, J.M.; et al. Preoperative Circulating Succinate Levels as a Biomarker for Diabetes Remission After Bariatric Surgery. Diabetes Care 2019, 42, 1956-1965. [CrossRef]

39. Astiarraga, B.; Martínez, L.; Ceperuelo-Mallafré, V.; Llauradó, G.; Terrón-Puig, M.; Rodríguez, M.M.; Casajoana, A.; Pellitero, S.; Megía, A.; Vilarrasa, N.; et al. Impaired Succinate Response to a Mixed Meal in Obesity and Type 2 Diabetes Is Normalized After Metabolic Surgery. Diabetes Care 2020, 43, 2581-2587. [CrossRef]

40. American Diabetes Association. 6. Glycemic targets: Standards of medical care in diabetes-2020. Diabetes Care 2020, 43 (Suppl. 1), S66-S76. [CrossRef]

41. Buse, J.B.; Wexler, D.J.; Tsapas, A.; Rossing, P.; Mingrone, G.; Mathieu, C.; D'Alessio, D.A.; Davies, M.J. 2019 update to: Management of hyperglycaemia in type 2 diabetes, 2018. A consensus report by the American Diabetes Association (ADA) and the European Association for the Study of Diabetes (EASD). Diabetologia 2019, 63, 221-228. [CrossRef]

42. Ricardo, A.C.; Yang, W.; Sha, D.; Appel, L.J.; Chen, J.; Krousel-Wood, M.; Manoharan, A.; Steigerwalt, S.; Wright, J.; Rahman, M.; et al. Sex-Related Disparities in CKD Progression. J. Am. Soc. Nephrol. 2018, 30, 137-146. [CrossRef]

43. Albertus, P.; Morgenstern, H.; Robinson, B.; Saran, R. Risk of ESRD in the United States. Am. J. Kidney Dis. 2016, 68, 862-872. [CrossRef]

44. Fernandez-Fernandez, B.; Mahillo, I.; Sanchez-Rodriguez, J.; Carriazo, S.; Sanz, A.B.; Sanchez-Niño, M.D.; Ortiz, A. Gender, Albuminuria and Chronic Kidney Disease Progression in Treated Diabetic Kidney Disease. J. Clin. Med. 2020, 9, 1611. [CrossRef] [PubMed] 
45. Yu, B.; Zanetti, K.A.; Temprosa, M.; Albanes, D.; Appel, N.; Barrera, C.B.; Ben-Shlomo, Y.; Boerwinkle, E.; Casas, J.P.; Clish, C.; et al. The Consortium of Metabolomics Studies (COMETS): Metabolomics in prospective cohort studies. Am. J. Epidemiol. 2019, 188, 991-1012. [CrossRef] [PubMed]

46. Unger, T.; Borghi, C.; Charchar, F.; Khan, N.A.; Poulter, N.R.; Prabhakaran, D.; Schutte, A.E. 2020 International Society of Hypertension Global Hypertension Practice Guidelines. Hypertension 2020, 75, 1334-1357. [CrossRef] [PubMed]

47. Mach, F.; Baigent, C.; Catapano, A.L.; Koskinas, K.C.; Casula, M.; Badimon, L.; Patel, R.S. 2019 ESC/EAS Guidelines for the management of dyslipidaemias: Lipid modification to reduce cardiovascular risk. Eur. Heart J. 2020, 41, 111-188. [CrossRef] 